Research Article

\title{
Control and Application of Terrain Curvature on Dynamic Disasters: A Case Study of Coal and Gas Outbursts in the Pingdingshan Mining Area, China
}

\author{
Dequan Sun, ${ }^{1,2}$ Ying Chen $\mathbb{D}^{1,3}$ Xiaoyan Li, ${ }^{1,2}$ Chunhui Huang, ${ }^{1,2}$ Huairui Su, ${ }^{1,2}$ \\ and Rujiao Chen ${ }^{1,4}$ \\ ${ }^{1}$ Engineering Laboratory of Deep Mine Rockburst Disaster Assessment, Jinan 250104, China \\ ${ }^{2}$ Shandong Provincial Research Institute of Coal Geology Planning and Exploration, Jinan 250104, China \\ ${ }^{3}$ Mining Engineering School, Liaoning Technical University, Fuxin 12300, China \\ ${ }^{4}$ The 3rd Exploration Team of Shangdong Coalfield Geologic Bureau, Taian 271000, China
}

Correspondence should be addressed to Ying Chen; 56724647@qq.com

Received 8 February 2021; Accepted 27 May 2021; Published 12 June 2021

Academic Editor: Gang Zhou

Copyright (C) 2021 Dequan Sun et al. This is an open access article distributed under the Creative Commons Attribution License, which permits unrestricted use, distribution, and reproduction in any medium, provided the original work is properly cited.

\begin{abstract}
Based on coal and gas outburst mining area topography, a risk evaluation index for mine dynamic disasters in relation to terrain curvature is presented by analyzing the terrain curvature formation and determining its classification and computational methods. Clarifying the mechanism that the terrain curvature changes reflects the intensity of tectonic activity and the tectonic stress field variation, as well as coal and rock mass energy storing. By using the $\mathrm{N}$-shaped landform in the Pingdingshan coal mine as a case study, an area having strong tectonic activity and coal and gas outbursts was recorded to occur where terrain curvature changed, notably occurring where the positive curvature radius was $80.21 \%$ of the total. These findings indicate that terrain curvature has significant controlling effects on coal and gas outbursts. A preliminary assessment for the occurrence risk of coal and gas outbursts using the terrain curvature value is proposed which can be used as an effective method to predict future outbursts.
\end{abstract}

\section{Introduction}

Coal and gas outbursts are a dynamic disaster that threatens safety production in coal mines. In 2020, five coal and gas outburst disasters occurred in mines in China, resulting in 22 deaths (accounting for $9.8 \%$ of total fatalities). Previous investigations have highlighted that more than 12 factors may influence the occurrence of coal and gas outbursts [1,2]. Influential factors include gas content [3], ground stress [4], and crushing effects [5].

Findings by Chang [6] recorded coal and gas outburst accidents in mining areas in China to be controlled by geological structures. For example, in the Yangquan area of the Shanxi province, the probability of coal and gas outbursts in structural areas peaked at $80 \%$ [3]. In the Huainan mining area in the Anhui province, coal and gas outbursts in crossholes and coal lanes near faults accounted for $71.8 \%$ of total outbursts [7]. In the Furong coal mining area in the Sichuan province, 47 coal and gas outburst accidents occurred near faults and folds [8]. Systematical analysis performed by Cheng-gong and Wang [9] summarizing coal and gas outbursts from 106 coal mines in 15 coalfields in China recorded 2525 outbursts ( $81.9 \%$ of a total of 3082 outbursts) to have occurred in locations with geological structures, such as faults, folds, magmatic intrusions, and variations in coal seam thickness. Only $557(18.1 \%)$ outbursts occurred in areas without geological structures.

The control mechanism of the geological structure and tectonic stress field on coal and gas outbursts has been previously investigated. For example, Han et al. $[1,2,10]$ 
conducted a series of surveys on coal mines in northeastern, North, and South China. According to the characteristics of gas occurrence, the distribution of tectonic stress, and the development of coal seams in structural belts, they reported that high tectonic stress of geological structural belts provides energy for the occurrence of coal and gas outbursts. As the migration and diffusion of coal seam gas were inhibited, the combination of high tectonic stress and high gas pressure resulted in suitable conditions for the incubation of coal and gas outbursts. Zhang et al. [11, 12] classified the type of occurrence by analyzing the control effect of the geological structure on coal and gas outbursts, thereby considering the occurrence of gas to be controlled by the coal seam geological structure. Based on theoretical discussion, $\mathrm{Xu}$ et al. [13] compared and analyzed the mechanism of different tectonic stress fields on coal and gas outbursts. Zhang $[14,15]$ proposed and confirmed a set of methods for evaluating and predicting the risk of coal and gas outbursts based on geological tectonic activities and plate tectonics. Gray and Yan et al. [16, 17], Sato and Fujii [18], and Pan and Cao et al. [4, 19], based on their belief that gas-bearing structural coal is the key condition for coal and gas outbursts, elaborated on the control mechanisms for coal and gas outburst structures.

Tectonic traces are the results of crustal stress; different tectonic traces reflect tectonic activities and tectonic stress fields with different characteristics. It has been previously shown that the basic form and main features of topography and geomorphology depend on the form of geological structures, which are closely related to dynamic disasters in mines [20]. Mining practices in many mining districts in China indicate that rock bursts and coal and gas outbursts generally occur in tectonically active areas [21]. As change characteristics of topography can reflect the geological form and activity, it is therefore possible to predict tectonically active areas prone to dynamic disasters by examining topography and landform changes.

Terrain curvature is a physical index that reflects the shape and concave-convex changes of the terrain surface in each cross section. It was studied for different targets in the literature, such as spatial variability of soil attributes [22], topographic feature [23], hydraulic conductivity [24], temperature [25], and snowslide [26]. However, the dynamic disaster-related terrain curvature is rare in the literature.

Terrain curvature variation is an external manifestation of geological tectonic activity, with its amplitude reflecting tectonic activity intensity. The value of terrain curvature reflects the severity of tectonic activity. If the value of terrain curvature sharply increases or decreases, it indicates that the area is highly affected by tectonic activities; if there is little or no change in terrain curvature, tectonic activity is regarded as being relatively weak. Therefore, the risk of coal and gas outbursts and other dynamic disasters in mines can be preliminarily judged using terrain curvature. Practical application examining terrain curvature changes in the Pingdingshan mining district shows that it plays a significant role in the occurrence of coal and gas outbursts and that it can be used as an effective method to predict coal and gas outbursts.

\section{Formation and Classification of Terrain Curvature}

2.1. Formation of Terrain Curvature. Earth's dynamic forces result in the movement and collision of tectonic plates, leading to a change in crustal structure and deformation and the dislocation of internal materials, resulting in different structural surface forms. Differences in morphology can be described by topographic curvature, one of the main parameters reflecting structures in the terrain surface, as well as being the basic variable of surface process simulation, soil erosion simulation, and land-use classification [20]. Topographic curvature can reflect the shape and concave-convex changes of the terrain surface in each cross section, as well as terrain structure and morphology. Different topographic curvature values represent the complexity of different structural parts and surface morphology changes.

Coal measure strata are composed of sedimentary rocks, and the primary structure is relatively simple. However, subsequent geological tectonic movement has changed their environmental conditions, forming folds, joints, faults, cleavage, and other structural forms. These structural changes have an important impact on the complexity of strata and the occurrence of dynamic disasters, as well as resulting in corresponding surface manifestations. Changes in topographic curvature are one external manifestation of tectonic activities.

2.2. Classification of Terrain Curvature. As terrain curvature can reflect the shape and deformation characteristics of an adjacent area using a surface point, it can therefore be used to study deformation characteristics, structural styles, and expansibility of surface morphology. The attributes of terrain curvature can be divided into onedimensional and two-dimensional curvature attributes. A one-dimensional curvature attribute is calculated by the univariate derivative, and it is mainly displayed as curves, which can directly reveal the physical form of an anticline and syncline. For complex surface morphology, surface curvature is usually calculated using the binary partial derivative as

$$
k=\frac{\mathrm{d}^{2} y}{\mathrm{~d} x^{2}}\left[1+\left(\frac{\mathrm{d} y}{\mathrm{~d} x}\right)^{2}\right]^{-(2 / 3)}
$$

The surface curvature of a terrain is a function of a point position. Different curves passing through the same point have different curvature expressions. For a point on the ground, minimum, maximum, and average curvature are the inherent properties of the terrain surface. They are independent of the coordinate system, and they belong to the first type of curvature. The second type of curvature is related to research contents, such as topography surface structure, groundwater, and sediment movement, mainly including section curvature, contour curvature, and tangent curvature (Figure 1). The curvature of a profile is the slope change rate in the maximum direction of a slope, and the curvature of a plane is the change rate in the direction of contour lines. The 


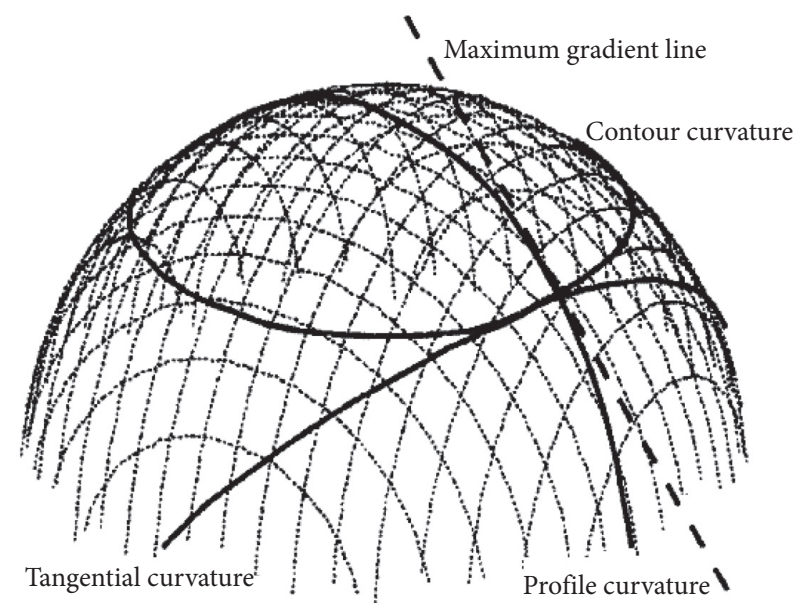

Figure 1: Definition of the profile, contour, and tangential curvature.

curvature of a tangent is the change rate in the direction perpendicular to the maximum direction of the slope [27].

Terrain curvature is usually calculated by the curvature of the longitudinal section; structural characteristics can be described quantitatively by determining the increase or decrease of the slope change rate along the gradient direction of each point. A positive result indicates the curvature of a depression area; negative results indicate the curvature of an uplift area; and a result of zero indicates a flat area or a monoclinic structure. The relationship between terrain change and curvature is shown in Figure 2. When $k>0$, the terrain is concave down, and when $k<0$, the terrain is convex up. At the inflection point, $k=0$, and the curvature before and after this point differs by having positive or negative characteristics.

\section{Method Application in the Pingdingshan Mining District}

3.1. General Geology of the Pingdingshan Mining District. The Pingdingshan mining district is situated in a late $\mathrm{Pa}$ leozoic coal accumulation basin in the southern margin of the North China block. This mining district belongs to the Shanxian-Pingdingshan fault depression in the northern part of the Xiaoxiong tectonic zone. From the Mesozoic to the Cenozoic, this district was controlled by the North China block, influenced by uplift of the orogenic belt in the Qinling Mountains. From the middle Yanshanian to the Himalayan, this district was repeatedly compressed and sheared by the Qinling Mountains' orogenic belt from the south to the north, which belonged to a high tectonic stress area. The Pingdingshan mining district is surrounded by depressions, with a raised area in the middle. This area had a general $\mathrm{N}$-shaped landform (Figure 3 ), indicating a strong history of tectonic activity.

\subsection{Terrain Curvature Application and Its Impact on Coal and} Gas Outbursts in the Pingdingshan Mining Area. By using elevation points and contour information from topographic

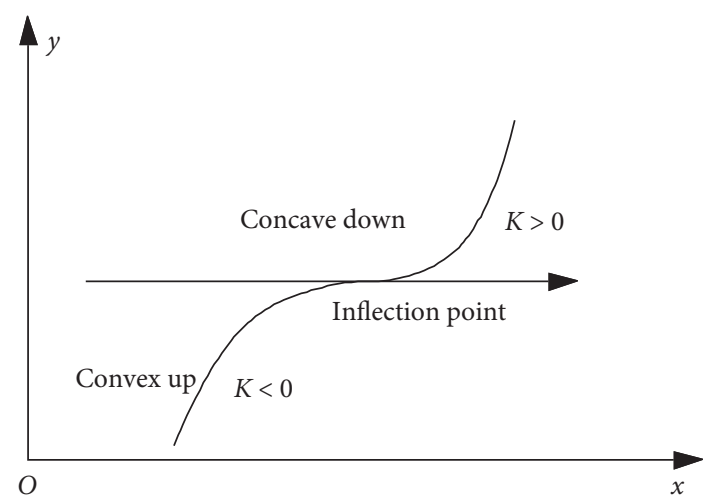

FIgURE 2: The relationship between terrain change and curvature.

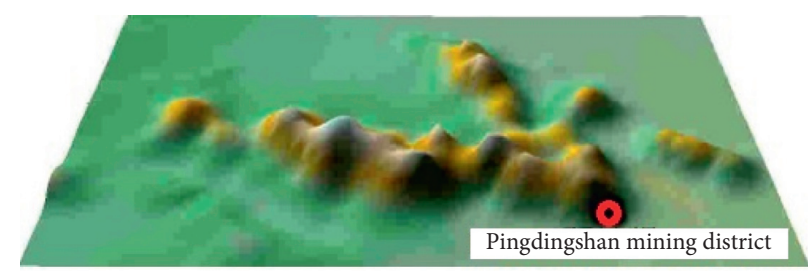

FIgURE 3: Three-dimensional topography of the Pingdingshan mine field.

maps, curvature value for the Pingdingshan mining district was calculated using the longitudinal profile curvature algorithm (Figure 4).

By taking the position of the main shaft as the reference object, six mines in the study region (nos. 12, 10, 8, 6, 4, and 1) have a maximum curvature value varying from $5.98 \times 10^{-5}$ to $12.8 \times 10^{-5}$; the other mines (nos. $13,11,9,7,5,3$, and 2 ) are situated in regions with small changes in curvature, ranging from $5.34 \times 10^{-11}$ to $1.08 \times 10^{-10}$. However, with the expansion of the mining area and an increase in mining depth, the corresponding regions will be affected by the change of terrain curvature.

Based on the map of terrain curvature in the Pingdingshan mining district, profiles along the dip of mine nos. 10 and 8 were made (Figures 5 and 6). Coal and gas outburst areas highlighted in mine no. 10 were completely within the range of the curvature change zone. Six of the 30 coal and gas outbursts occurred in the maximum curvature area, accounting for $20 \%$ of total outbursts. The coal and gas outburst area in mine no. 8 was slightly larger than that of the curvature change zone; 20 of 43 coal and gas outbursts occurred in the area with maximum curvature, accounting for $46.5 \%$ of the total.

In order to quantitatively evaluate the influence of terrain curvature on coal and gas outbursts in the Pingdingshan mining district, curvature radius was introduced. The radius of curvature $(R)$ was calculated as

$$
R=\frac{1}{k}
$$

Coal and gas outbursts in the Pingdingshan mining district were mainly distributed in the positive curvature 


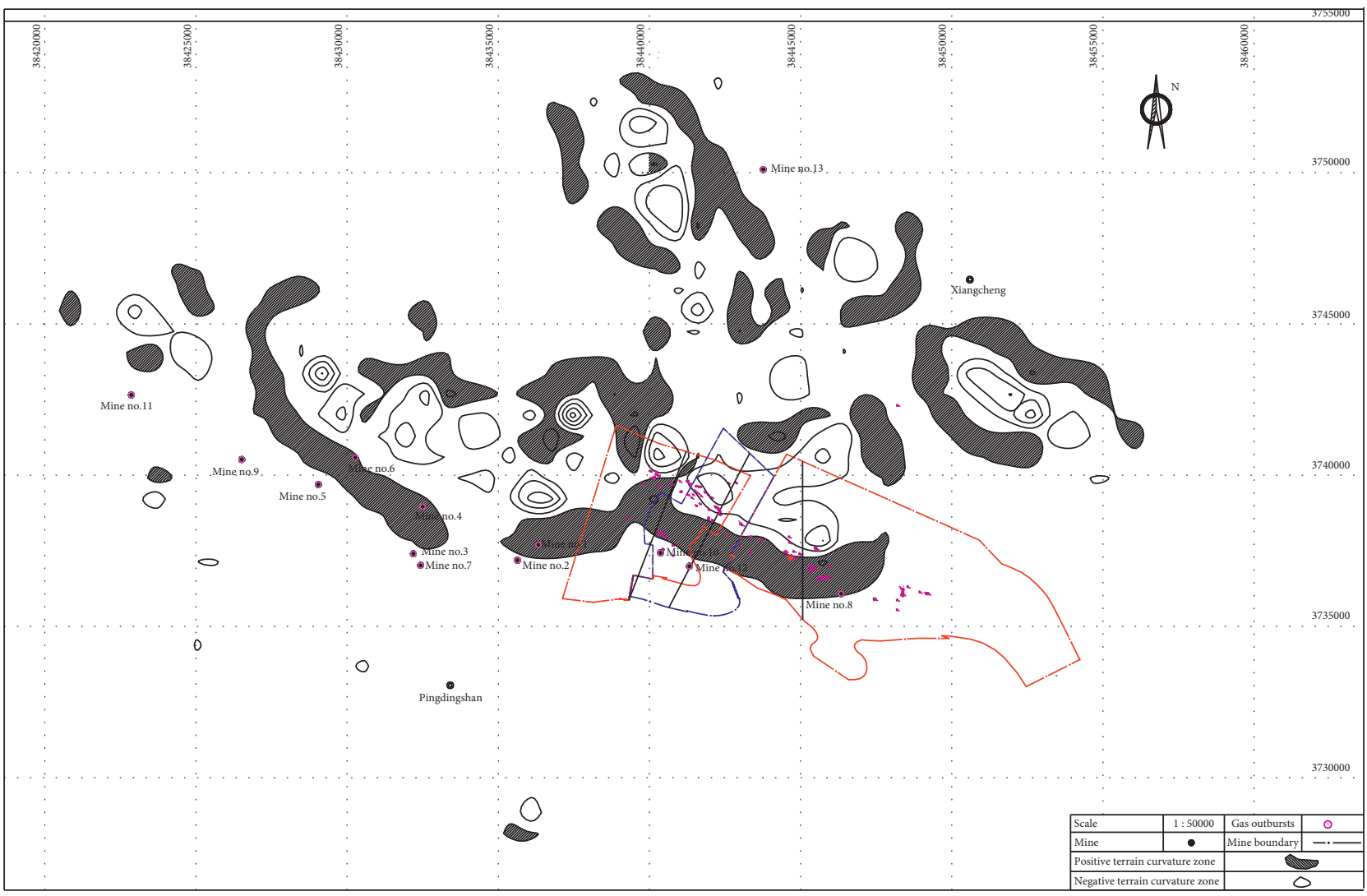

Figure 4: Terrain curvature change diagram for the Pingdingshan mine.

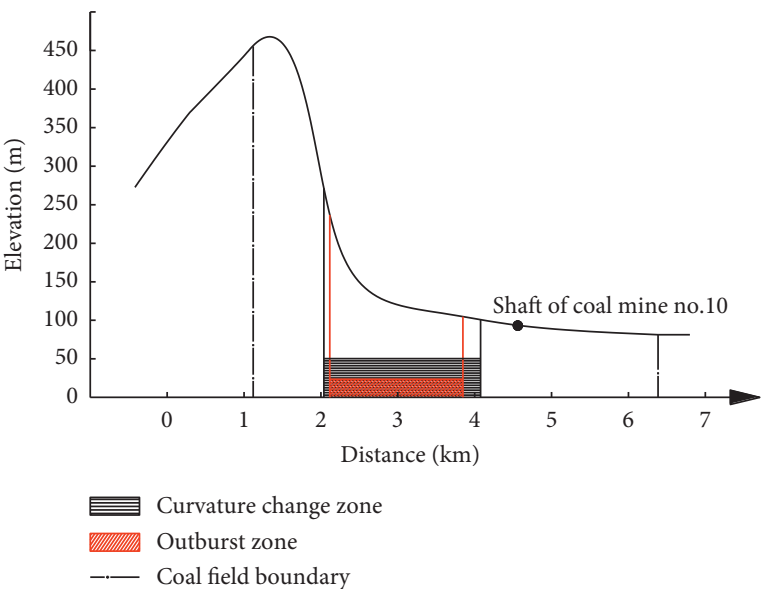

Figure 5: Relationship between terrain curvature change and coal and gas outbursts in mine no. 10.

radius region (Figure 7), with 96 coal and gas outbursts occurring in the penta and hexynoic acid coal seams. Among these, 77 outbursts occurred within the radius of a positive curvature, accounting for $80.21 \%$ of the total; 19 outbursts $(19.79 \%)$ occurred within the radius of a negative curvature. These results show that coal and gas outbursts in the Pingdingshan mining district mainly occur in an area of positive curvature terrain, i.e., the concave terrain area

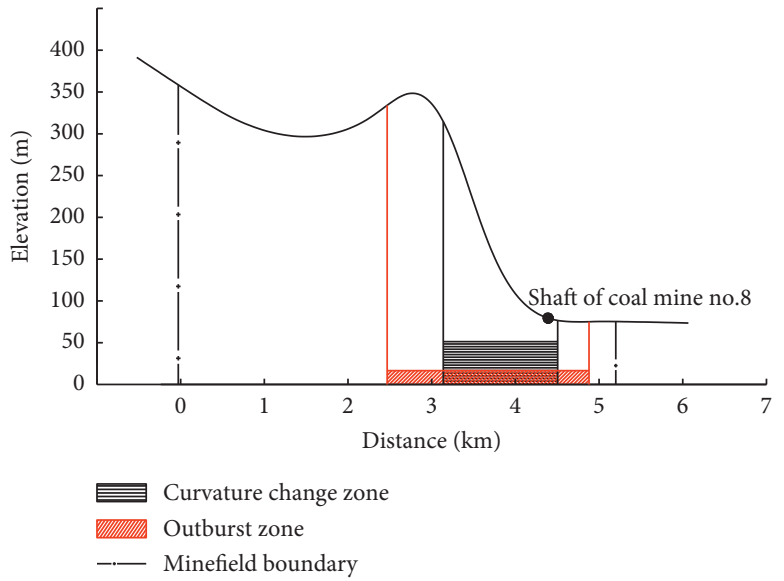

FIgURE 6: Relationship between terrain curvature change and coal and gas outbursts in mine no. 8 .

which is significantly affected by a regional tectonic stress field is conducive to energy accumulation and gas storage. When reaching the critical energy of coal and rock mass failure, coal and gas outbursts will occur under the influence of external mining disturbance and other factors. As the convex area corresponding to negative curvature topography is not conducive to the accumulation and storage of energy, relatively fewer coal and gas outbursts therefore occur. 


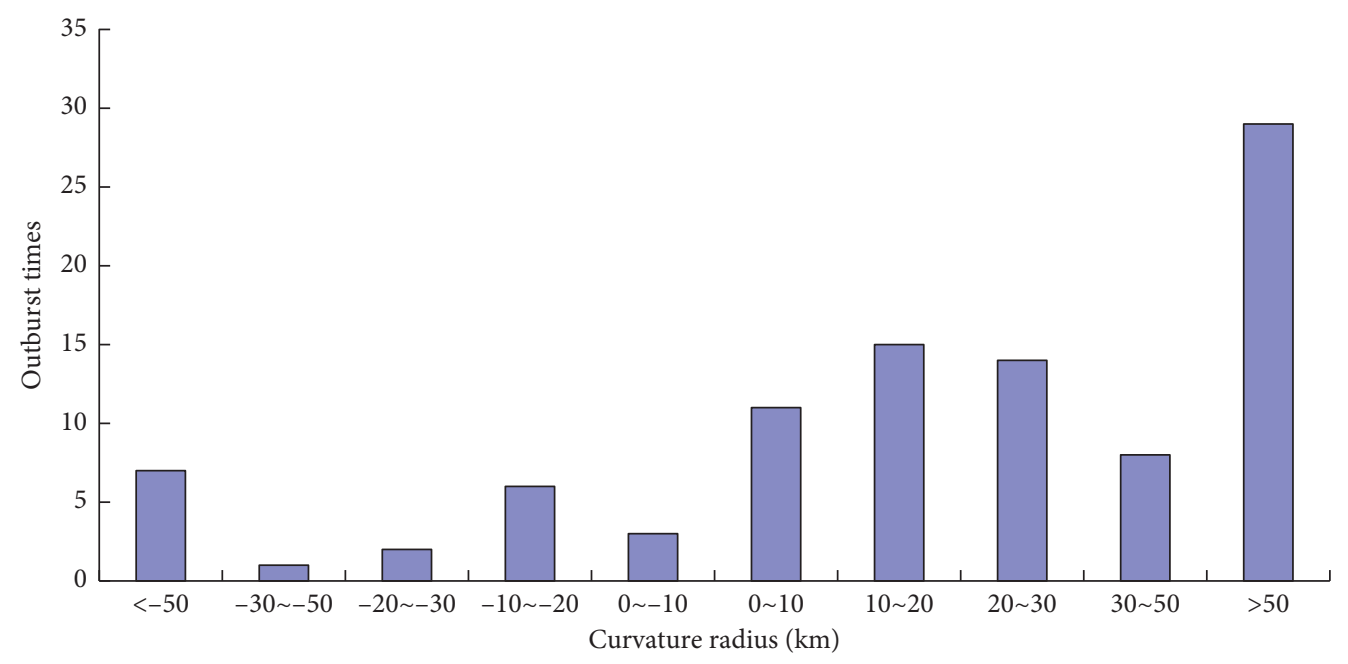

FIgURE 7: The relationship with curvature radius and outburst number in the Pingdingshan east mine.

\section{Discussion}

(1) So far, many methods are used to predict mine dynamic disasters [5, 28-31]. Compared with others, terrain curvature method has the following characteristics. According to the terrain elevation data that are very convenient to obtain from the National Geomatics Center of China, the terrain curvature map can be drawn after processing. Accordingly, the changes in curvature can delineate areas or locations with high risk of dynamic disasters. Therefore, the terrain curvature to predict mine dynamic disasters has high efficiency, low cost, and easy operation.

(2) The practical project showed that terrain curvature change has an important impact on coal and gas outbursts in mines, and the incidence on coal and gas outbursts can be judged by the terrain curvature value. According to our results, the risk of coal and gas outbursts in different areas can be predicted. Based on these findings, it is possible to rationally optimize the mining layout or to undertake preventive measures before mining commences in a high-risk region, thus minimizing the risks associated with mining. Our findings are also important for predicting and preventing coal and gas outbursts.

(3) Coal and gas outbursts are not only related to the change of topographic curvature but also affected by other factors, such as gas production, mechanical properties, and elastic potential of coal rocks. Therefore, coal and gas outbursts may not necessarily occur in areas where terrain curvature drastically changes, and coal and gas outbursts may also occur in areas where the change of terrain curvature is not obvious. In practical engineering applications, it is necessary to combine multiple factors to undertake a comprehensive analysis. However, predicting the risk of coal and gas outbursts and other dynamic disasters based on the change of terrain curvature is important to improve mine safety.
(4) Numerous research results show that coal and gas outbursts and rock bursts are affected by tectonic activities. Terrain curvature reflects the tectonic activities' intensity. So, the terrain curvature is appropriate to predict coal and gas outbursts and rock bursts.

\section{Conclusions}

(1) The occurrence of dynamic disasters in mines is closely related to geological structures. Topography and landform can reflect the form and activity characteristics of geological structures. Therefore, analysis of topographic changes can be used before mining commences to predict the risk of dynamic disasters.

(2) The change of terrain curvature reflects the intensity and stress distribution of tectonic activities. The risk of coal and gas outbursts and other dynamic disasters in mines can also be preliminarily judged according to the value of the terrain curvature.

(3) Terrain curvature in the Pingdingshan mining district significantly varies. Coal and gas outburst events indicate that terrain curvature plays a significant role in their occurrence. $80.21 \%$ of coal and gas outbursts have occurred within the radius of a positive curvature. The practice has proved that terrain curvature can be used as an effective method to predict coal and gas outbursts.

\section{Data Availability}

The data used to support the findings of this study are included within the article.

\section{Conflicts of Interest}

The authors declare that they have no conflicts of interest. 


\section{Acknowledgments}

This study was financially supported by the National Natural Science Foundation of China (Grant nos. 51874164, 51704148, and 51674135), National Key R\&D Program of China (Grant no. 2017YFC0804203), Open Projects of Engineering Laboratory of Deep Mine Rockburst Disaster Assessment (Grant no. (2020)011), and Major Scientific and Technological Innovation Projects in Shandong Province (Grant no. 2019SDZY02). The authors are also grateful to EditSprings (https://www.editsprings.com/) for their linguistic services.

\section{References}

[1] J. Han, H. Zhang, and P. Zhang, "Nappe structure's kinetic features and mechanisms of action to coal and gas outburst," Journal of China Coal Society, vol. 37, no. 2, pp. 247-252, 2012, in Chinese.

[2] J. Han, H. Zhang, and W. Song, "Coal and gas outburst mechanism and risk analysis of tectonic concave," Journal of china Coal Society, vol. 36, no. S1, pp. 108-113, 2011, in Chinese.

[3] J. Luo, Study on Energy Source and Energy Dissipation Mechanism of Coal and Gas Outburst, Chongqing University, ChongQing, China, 2017, in Chinese.

[4] X. Pan, Study on Mechanism of Coal and Gas Outburst in Tectonic Regions, Chongqing University, Chongqing, China, 2019, in Chinese.

[5] J. Chen, J. Gao, and Y. Pu, "Machine learning method for predicting and warning of rockbursts," Journal of Mining and Strata Control Engineering, vol. 3, no. 1, in Chinese, Article ID 13026, 2021.

[6] Z. Chang, Research on Gas and Coal Dynamic Disaster at the Condition of High Geo-Stress in Deep Coal Seam in Zhujixi Mine, China University of Mining and Technology, Beijing, China, 2017, in Chinese.

[7] C. Pan, Study on Mechanism of Fault Activation Induced Coal and Gas Outburst under the Influence of Mining, Guizhou University, Guiyang, China, 2015, in Chinese.

[8] M. Bo. Zhang, M. Lin, and D. Zhou, "Stress evolution law of coal in tunneling face and its application," Coal Technology, vol. 37, no. 3, pp. 10-13, 2018, in Chinese.

[9] C. Cheng-gong and Y. Wang, "Qualitative and quantitative analysis of general regularity of coal and gas outburst," China Safety Science Journal, vol. 14, no. 6, pp. 109-112, 2004, in Chinese.

[10] J. Han and H. Zhang, "The controlling of tectonic evolution to coal and gas outburst," Journal of China Coal Society, vol. 35, no. 7, pp. 1125-1130, 2010, in Chinese.

[11] Y. Zhang and Z. Zhang, "Three grades of gas-geological maps and their application to gas controlling," Journal of China Coal Society, vol. 4, pp. 455-458, 2005, in Chinese.

[12] Z. Zhang and Y. Wu, "Tectonic-level-control rule and areadividing of coalmine gas occurrence in China," Earth Science Frontiers, vol. 20, no. 2, pp. 237-241, 2013, in Chinese.

[13] F. Y. Xu, X. Zhu, and G. Wang, "The quantitative research on the palaeotectonic stress field and its control to coal and gas outburst," Chinese Journal of Geology, vol. 1, pp. 71-84, 1995, in Chinese.

[14] H. Zhang, "Study of active faults and forecast of dynamic phenomena in mines," Journal of China Coal Society, vol. 23, no. 2, pp. 113-118, 1998, in Chinese.
[15] H. Zhang, "Application of geo-dynamic division method in prediction of coal and gas outburst region," Chinese Journal of Rock Mechanics and Engineering, vol. 4, pp. 621-624, 2003, in Chinese.

[16] I. Gray, Outburst Risk Determination and Associated Factors, Australian Coal Research Ltd, Brisbane, Australia, 2015.

[17] J. Yan, X. Zhang, and Z. Zhang, "Research on geological control mechanism of coal-gas outburst," Journal of China Coal Society, vol. 38, no. 7, pp. 1174-1178, 2013, in Chinese.

[18] K. Sato and Y. Fujii, "Source mechanism of a large scale gas outburst at sunagawa coal mine in Japan," Pure and Applied Geophysics, vol. 129, no. 3, pp. 325-343, 1989.

[19] Y. Cao, D. He, and C. Glick David, "Coal and gas outbursts in footwalls of reverse faults," International Journal of Coal Geology, vol. 48, no. 1-2, pp. 47-63, 2001.

[20] X. jun. Liu, Ye. Wang, and Z. Cao, "Error analysis on DEMbased terrain curvatures models," Science of Surveying and Mapping, vol. 31, no. 5, pp. 50-53, 2006, in Chinese.

[21] H. Zhang, J. Han, and W. Song, Geo-dynamic Division, China Coal Industry Publishing House, Beijing, China, 2009, in Chinese.

[22] G. L. D. Santos, M. G. Pereira, S. S. D. Lima, M. B. Ceddia, V. M. M. Mendonca, and R. C. Delgado, "Landform curvature and its effect on the spatial variability of soil attributes," Cerne, vol. 22, no. 4, pp. 431-438, 2016.

[23] M. Vallejo Orti, "Comparison of three algorithms for the evaluation of TanDEM-X data for gully detection in krumhuk farm (Namibia)," Remote Sensing, vol. 11, no. 11, p. 1327, 2019.

[24] M. Niedda, "Upscaling hydraulic conductivity by means of entropy of terrain curvature representation," Water Resources Research, vol. 40, no. 4, Article ID W04206, 2004.

[25] L. Lindkvist and D. Chen, "Air and soil frost indices in relation to plant mortality in elevated clear-felled terrain in Central Sweden," Climate Research, vol. 12, no. 1, pp. 65-75, 1999.

[26] P. Krebs, M. Stocker, G. B. Pezzatti, and M. Conedera, “An alternative approach to transverse and profile terrain curvature," International Journal of Geographical Information Science, vol. 29, no. 4, pp. 643-666, 2015.

[27] Y. Wang, Error Analysis of Terrain Curvatures Based on Grid DEM, Changsha University of Science \& Technology, Changsha, China, 2005, in Chinese.

[28] Y. Cheng and H. Zhou, "Research progress of sensitive index and critical values for coal and gas outburst prediction," Coal Science and Technology, vol. 49, no. 1, pp. 146-154, 2021, in Chinese.

[29] H. Jiang, L. Dou, and S. Gong, "Rock burst assessment and prediction by dynamic and static stress analysis based on micro-seismic monitoring," International Journal of Rock Mechanics and Mining Sciences, vol. 93, pp. 46-53, 2017, in Chinese.

[30] Y. Pu, D. B. Apel, and B. Lingga, "Rockburst prediction in kimberlite using decision tree with incomplete data," Journal of Sustainable Mining, vol. 17, no. 3, pp. 158-165, 2018.

[31] R. Shukla, M. Khandelwal, and P. K. Kankar, "Prediction and assessment of rock burst using various meta-heuristic approaches," Mining, Metallurgy \& Exploration, vol. 38, pp. 1375-1381, 2021. 